\title{
Aprendizagem Inter/Transdisciplinar das Áreas de Informática, Inglês e Ciências: construção do conhecimento através de aplicativos digitais livres
}

Jadson P. Rafalski ${ }^{1,2,3}$, Otávio L. Santos ${ }^{1,2}$, Elaine G. Silva ${ }^{2}$, Paula Freire Cezatti Albino Albani², Virgínia Caldas Machado²

${ }^{1}$ Departamento de Informática - Universidade Federal do Espírito Santo (UFES). Avenida Fernando Ferrari, 514, Goiabeiras - Vitória, ES, Brasil. CEP 29075-910.

${ }^{2}$ Centro de Educação a Distância - Instituto Federal do Espírito Santo (IFES). Rodovia ES-010, Km 6.5, Manguinhos, Serra, ES, Brasil. CEP 29173-087.

\author{
${ }^{3}$ Faculdade Novo Milênio \\ ${ }^{3}$ Campus Vila Velha - Av. Santa Leopoldina $n^{\circ} 840$ - Coqueiral de Itaparica - Vila \\ Velha/ES - CEP 29102-040 \\ \{olube,jrafalski\}@inf.ufes.br, \{elaineges, paulafreirecezatti,gicalm\}@hotmail.com
}

\begin{abstract}
In order to use the new information and communication technologies in education it is needed to rethink the traditional teaching. It is not a trivial task motivating students, even more about using technology. Aiming to contribute to this discussion, this work brings a proposal of an interdisciplinary Learning Project embracing English, Science and Informatics based on experiences obtained in field researches developed by students of a public school in the city of Vitoria, ES. Some educational software were chosen to promote authorship, cooperation and communication among the learners along with learning theories that were revised so as to support the activities.
\end{abstract}

Resumo. Para utilizarmos as novas tecnologias de informação e comunicação na educação é necessário repensar o ensino tradicional. Motivar os aprendizes nem sempre é tarefa trivial, ainda mais quando se trata de tecnologia. Visando contribuir para essa discussão, este trabalho traz a proposta de um Projeto de Aprendizagem interdisciplinar nas áreas de Inglês, Ciências e Informática, baseado nas experiências obtidas nos trabalhos de campo desenvolvidos por estudantes de uma escola pública municipal da cidade de Vitória/ES. Softwares educacionais foram escolhidos para promover autoria, cooperação e comunicação entre os envolvidos junto a teorias de aprendizagem que foram revistas para fundamentar as atividades realizadas. Os resultados obtidos foram satisfatórios e foi possível parceber que através do simples preparo dos docentes para o uso de novas tecnologias junto a suas atividades interdisciplinares tornou as aulas mais interativas e agradáveis para os estudantes.

\section{Introdução}

Alunos chegando, professores em expectativa. Mais um dia rotineiro. O conteúdo das disciplinas não é cativante para os alunos. Eles têm dificuldade em compreender a 
práxis. Projetos, vídeo, piquenique literário, música, poesia, exposição de trabalhos, aula de campo; as atividades mais interessantes para os alunos ocorrem raramente. Enquanto isso, subutilizado, um laboratório de informática com 20 computadores novos, quadro digital, internet banda larga, monitor especializado e softwares educativos recém-instalados. Aproximadamente 500 alunos esperando, ávidos, para usálo. Na mesma cena, um conjunto de professores desinformados quanto ao potencial educativo do repositório instalado, e, por consequencia, sem saber como, quando, para que e por que introduzir os recursos tecnológicos na prática pedagógica.

O preparo sistemático dos docentes em tecnologias da informação e comunicação busca preencher uma lacuna no ensino tradicional originada pelo abismo entre uma sociedade cibernética em ininterrupta modernização e a escola centrada, ainda, em quadro e livro, e, em algumas instâncias, aparelhos para reprodução de vídeo e som visando a construção do conhecimento. Por isso, a formação de professores em informática aplicada ao universo educacional objetiva prepará-los para efetiva atuação no âmbito escolar, capacitando-os a incluir no cotidiano Tecnologias da Informação e Comunicação (TICs) que apoiem oportunidades de trocas, possibilidades de interações do estudante com o professor [Bernadi e Behar, 2004]. É preciso, porém, atentar para o fato de que a tecnologia por si só não implica em ganhos significativos no aprendizado, fazendo-se necessário o apoio pedagógico para tal, que, neste trabalho, será visto com a realização de um Projeto de Aprendizagem (PA) [Fagundes, Sato e Maçada, 1999].

As TICs são ferramentas em permanente reconstrução, o que exige do professor, atento à multiplicação da ciência, envolvimento em formação continuada tanto em tecnologia quanto em sua área específica [Amaral et al., 2009]. Mais que isso, carece estudar as especificidades dos softwares educacionais disponíveis, primordialmente os de categoria livre, identificá-los e classificá-los com a finalidade de selecionar os que melhor suporte oferecem ao ensino-aprendizagem em sua área de conhecimento.

A escola contemporânea exige dos docentes o letramento digital, a familiarização com os instrumentos educacionais oferecidos num laboratório de informática na expectativa de inovar suas aulas, em consonância com a realidade do ensino público nacional, onde é necessária a utilização de softwares de cunho livre, como é o sistema operacional Linux.

Neste contexto, a Secretaria Municipal de Educação de Vitória adota em seus laboratórios de informática o Sistema Operacional Edubuntu, proveniente da distribuição Ubuntu, que possui como principais pacotes de softwares, os sistemas educativos. Desta forma, na rede pública municipal de ensino, os professores podem contar com a presença de 36 laboratórios de Informática localizados em Centros de Educação Infantil (CMEIs) e 52 em Escolas Municipais de Ensino Fundamental $(\text { EMEFs })^{1}$, todos operando aplicativos livres.

Visando aplicar essa variedade de recursos no planejamento de aulas genuinamente expressivas e contribuir para a inclusão digital no âmbito escolar, uma professora da rede municipal, que cursa Informática na Educação no Instituto Federal de

\footnotetext{
1 Informações recebidas via e-mail da Gerência de Educação Tecnológica da Secretaria Municipal de Educação da Prefeitura de Vitória em 15 maio 2012.
} 
Educação, Ciência e Tecnologia do Espírito Santo (IFES), observou um envolvimento muito grande dos alunos num projeto de Horta Escolar. Após dialogar com outra professora responsável pelo projeto, e ambas com os alunos, propuseram um projeto de aprendizagem inter/transdisciplinar, utilizando tecnologias da informação e comunicação para enriquecer esta experiência.

Neste artigo apresentaremos a proposta realizada em sala de aula, sua fundamentação teórica embasada num projeto de aprendizagem interdisciplinar, os métodos e recursos utilizados e os resultados obtidos com os trabalhos realizados até o presente momento.

\section{O Projeto de Aprendizagem sobre a Horta Escolar}

Projetos de Aprendizagem fundamentados em experiências significativas para os alunos são oportunidades áureas para a construção do conhecimento. De acordo com [Fialho, 2010] o professor "[...] pode e deve valer-se das tecnologias da informação e comunicação no sentido de tornar o ato de aprender algo motivador, interessante, envolvente e lúdico". No estabelecimento de ensino em foco, através da horta escolar, os alunos vivenciam atividades que envolvem o plantio, o cuidado e a colheita de hortaliças, frutas e plantas medicinais. Além disso, experimentam a aplicação de algumas ervas com propriedades medicinais cientificamente comprovadas para aliviar sintomas de enfermidades comuns como gripe e resfriado; pesquisam o valor nutritivo de verduras e frutas e sua importância para a manutenção da saúde e têm o contato com a terra através do preparo do canteiro e da separação de mudas para o cultivo doméstico. Fora da escola, repassam o conhecimento adquirido aos familiares e amigos.

O trabalho por projetos significa, também, transdisciplinaridade que é a integração das áreas de conhecimento - um processo de cooperação que visa a busca por uma nova compreensão da realidade a partir da articulação de componentes que ultrapassam suas especificidades. É um canal que "potencializa a integração de diferentes áreas de conhecimento, assim como a integração de várias mídias e recursos, os quais permitem ao aluno expressar seu pensamento por meio de diferentes linguagens e formas de representação" [Prado, 2003].

A professora de inglês, observando o interesse e a participação dos alunos do $7^{\circ}$ ano nas atividades da horta que é monitorada pela professora de ciências, vislumbrou um cenário propício para a contextualização de atividades inter/transdisciplinares com a inclusão das TICs. Segundo [Almeida, 2010], "importante é que o professor tenha oportunidade de reconhecer as potencialidades pedagógicas das TICs e aí assim incorporá-las à sua prática.

As TICs apresentam opções interativas para a instrumentalização e o compartilhamento do saber, com suporte midiático para a organização, registro e interação criativa do aprendizado. $O$ computador deve ser um recurso que deve ser usado para fazer tarefas que despertem o interesse dos estudantes. Usar essas novas tecnologias como um meio de estabelecer uma relação com a realidade e, no caso de uma horta escolar, um meio de apresentar o trabalho dos estudantes à suas famílias e comunidades.

A inserção do idioma inglês ocorreu de modo natural, considerando que a ambientação da horta escolar produziu ganchos para a inclusão digital atrelada à exploração linguística bilíngue, pois os alunos não só insistem em ter aulas no 
laboratório de informática, como fazem frequentes perguntas à professora de inglês com relação ao vocabulário e expressões relacionadas a sua vivência.

Este panorama representa o cenário sobre o qual o PA foi fundamentado, cujo objetivo foi integrar as aulas de ciências, inglês e informática de forma interdisciplinar, possibilitando a divulgação dos trabalhos e resultados encontrados a cada aula, na Internet. E que poderiam ser vistos e analisados, tantos pelos próprios colegas como pela comunidade na qual os estudantes se encontram inseridos. $\mathrm{O}$ interesse dos alunos nas atividades educativas da horta escolar, a curiosidade pela língua inglesa, e o anseio de usarem os computadores encaminhou para a idealização desta iniciativa inter/transdiciplinar, demostrando que o "[...] trabalho com projetos é a produção colaborativa de conhecimento", [Almeida e Prado, 2008].

\section{O Método}

Subdividimos, para questões de simplificação, o trabalho em quatro etapas que são descritas neste capítulo.

\subsection{Etapa 1}

A Etapa 1 correspondeu à escolha dos aplicativos que poderiam melhor promover a aprendizagem de uma ou mais áreas do conhecimento através de atividades interdisciplinares.

Tendo em vista a diversidade de aplicativos disponibilizados pelo Edubuntu, foram selecionados pelos professores alguns que supostamente permitiriam a consecução das atividades de modo inter/transdisciplinar nas áreas em foco. Numa préseleção realizada, cinco foram selecionados: HagáQuê, EdiLim, JClic, Freemind e Scratch. O estudo buscará verificar a integração entre usabilidade e aprendizagem, de forma a atender aos objetivos propostos entre as áreas envolvidas no projeto.

A descrição dos softwares escolhidos, bem como uma breve avaliação dos mesmos segundo critérios de avaliação de sistemas educacionais é mostrada mais a diante, quando tratarmos os recursos necessários para a realização do PA.

\subsection{Etapa 2}

A Etapa 2 correspondeu à apresentação dos aplicativos escolhidos, aos estudantes. As ferramentas propostas correspondem a Objetos de Aprendizagem Vituais, que são definidos por [Spinelli, 2007 apud Audino e Nascimento, 2010] abaixo:

Um objeto virtual de aprendizagem é um recurso digital reutilizável que auxilie na aprendizagem de algum conceito e, ao mesmo tempo, estimule o desenvolvimento de capacidades pessoais, como, por exemplo, imaginação e criatividade. [Spinelli, 2007 apud Audino e Nascimento, 2010].

Sendo quase todos inteiramente desconhecidos aos alunos, fez necessária a apresentação de forma prática da usabilidade dos softwares selecionados. O grande tema da horta escolar foi escalonado em sub-temas para estudo e compreensão de cada tópico, devidamente acompanhados pelos professores das áreas envolvidas.

\subsection{Etapa 3}


A Etapa 3 correspondeu ao suporte para a instrumentalização dos conhecimentos e ensaios vivenciados na horta escolar.

Resumidamente, os professores das disciplinas envolvidas levaram o aluno a aprender como cultivar frutas, vegetais e ervas medicinais, como utilizar a tecnologia disponível para a consolidação e divulgação do aprendizado, e isto, em língua nativa e em inglês, abrangendo assim as áreas de ciências e línguas estrangeiras.

\subsection{Etapa 4}

Nesta etapa os estudantes, orientados por seus professores, foram autores do conhecimento ao realizarem, com auxílio das ferramentas propostas, as seguintes atividades:

- Criação de histórias em quadrinhos (bilingue) exprimindo fatos vivenciados nas visitas a horta escolar;

- Criação de um livro de receitas (bilingue) - receitas preparadas pelos alunos ou pelas merendeiras da escola, com produtos colhidos na horta escolar;

- Criação de um livro de histórias (bilingue) contando as experiências marcantes proporcionadas pelo trabalho desenvolvido na horta escolar;

- Criação de jogos (quebra-cabeça, caça-palavras, jogo de memória) contendo o conteúdo aprendido na disciplina de ciências.

Os recursos que possibilitaram o desenvolvimento das etapas especificadas serão apresentados a seguir, junto aos demais recursos necessários para a elaboração do PA junto aos aprendizes.

\section{Recursos}

Neste capítulo serão apresentados os recursos necessários para a realização do PA descrevendo as peculiaridades de cada um. Para facilitar o entendimento, decidiu-se separá-los segundo as áreas envolvidas no projeto, como segue abaixo.

\subsection{Recursos de Informática}

Alguns dos recursos de informática utilizados já foram previamente citados, como os computadores da sala de informática e os softwares educacionais propostos na realização das atividades dos aprendizes. Estes constituem os recursos técnicos do PA, que necessitaram acompanhamento do professor de Informática, cuja função é manter o funcionamento da estrutura técnica do PA. Segue a descrição dos softwares utilizados, bem como uma avaliação dos mesmos quanto a possibilidade de aplicação na educação.

HagáQuê: é um editor de histórias em quadrinhos, distribuído gratuitamente, que possibilita ao aluno criar a sua própria $\mathrm{HQ}$, possui um banco de imagens com os diversos componentes para a construção de uma história por exemplo: cenário, personagens, balões, entre vários recursos de edição de imagens.

EdiLim: é um ambiente para criação de materiais educativos, que suporta vários elementos multimédia, propiciando a interação de texto, som, vídeo e imagens. Os arquivos estão na web, não se instala nada no computador, o acesso imediato na internet. Independente do sistema operativo, hardware e navegador web.

Jclic: é uma ferramenta para criação da atividades didádicas, onde o professor cria suas atividades baseando-se em pré-formatos como quebra-cabeças, jogos da 
memória, de completar palavras, de relacionar palavras e figuras, e outros, inserindo seu próprio conteúdo.

FreeMind: permite passar todas estas idéias para liberar nossa mente de preocupações e ansiedades, graças um sistema que provê uma série de mapas conceituais (mind maps ou traduzindo literalmente, mapas de mente), que são uma espécie de gráficos com distintos formatos para armazenar idéias e conceitos, em forma de informação relacionada.

Scratch: A ferramenta de desenvolvimento foi o software Scratch, desenvolvido pelo MIT (Massachusetts Institute of Tecnology). Este possibilita a criação de vídeos, jogos, animações, músicas e arte. Por meio de uma interface visual é possível programar utilizando conexões de blocos, que correspondem a comandos.

Visando garantir que os softwares ajudariam os estudantes em seu aprendizado, fez-se uma avaliação dos mesmos segundo o método de avaliação de Reeves, TICESE, e o método Ergolist [Silva, 1998], que contempla os aspectos pedagógicos e ergonômicos.

A avaliação resultou, portanto, na seguinte tabela, onde definimos uma nota qualitativa a ser atribuida a cada software educativo, segundo a conformidade com cada requisito, que for a, quanto ao atendimento ou não do requisito: [3] - sempre, [2] muitas vezes, [1] - poucas vezes, [0] - nunca, [N] - não se aplica / não suporta o requisito:

\begin{tabular}{|l|c|c|c|c|c|}
\hline Requisitos/Softwares & HagáQuê & EdiLim & JClic & Freemind & Scratch \\
\hline Apresentação & $\mathrm{N}$ & 0 & 3 & 3 & 3 \\
\hline Consulta & $\mathrm{N}$ & 0 & 3 & 3 & 3 \\
\hline Pergunta / Resposta & $\mathrm{N}$ & 1 & 3 & $\mathrm{~N}$ & 1 \\
\hline Tutor Inteligente & $\mathrm{N}$ & 0 & 3 & $\mathrm{~N}$ & 1 \\
\hline Construção & 3 & 3 & 3 & 3 & 3 \\
\hline Jogo & $\mathrm{N}$ & 2 & 3 & $\mathrm{~N}$ & 3 \\
\hline Simulação & $\mathrm{N}$ & 0 & 3 & $\mathrm{~N}$ & 3 \\
\hline Micromundo & $\mathrm{N}$ & 0 & $\mathrm{~N}$ & $\mathrm{~N}$ & 3 \\
\hline Programação & $\mathrm{N}$ & 2 & 2 & $\mathrm{~N}$ & 3 \\
\hline Comunicação & $\mathrm{N}$ & 1 & 3 & 3 & 3 \\
\hline Cooperação & $\mathrm{N}$ & 1 & 3 & 2 & 1 \\
\hline Presteza & 3 & 1 & 3 & 3 & 3 \\
\hline Agrupamentos & 3 & 2 & 3 & 2 & 3 \\
\hline Feedback Imediato & 2 & 2 & 2 & 2 & 3 \\
\hline Ações Explícitas & 3 & 3 & 3 & 3 & 3 \\
\hline Controle do Usuário & 3 & 2 & 3 & 1 & 3 \\
\hline Consistência & 3 & 2 & 3 & 3 & 3 \\
\hline Significado & 2 & 2 & 3 & 2 & 3 \\
\hline Lembrar & 3 & 3 & 3 & 3 & 3 \\
\hline Entender & 3 & 3 & 3 & 3 & 3 \\
\hline Aplicar & 3 & 3 & 3 & 3 & 3 \\
\hline Analisar & 3 & 3 & 3 & 3 & 3 \\
\hline Avaliar & 3 & 3 & 3 & 3 & 3 \\
\hline Criar & 3 & 3 & 3 & 3 & 3 \\
\hline
\end{tabular}

Tabela 1: Avaliação dos softwares quanto suas características. 
Esta avaliação será melhor comentada na análise dos resultados, onde analisaremos se os softwares utilizados realmente contribuíram para a construção do conhecimento dos estudantes.

\subsection{Recursos de Ciências}

Os recursos da área de Ciências foram os que motivaram a realização deste trabalho, como descrito em nossa justificativa. O maior deles é a horta escolar, onde são cultivadas várias ervas e plantas para estudo de suas propriedades. Deve-se ainda considerar o material didático das crianças, através do qual terão um primeiro momento com a teoria estudada, partindo assim para o computador. Como recurso humano de extrema importância, o professor de Ciências tem grande responsabilidade de mediar o aprendizado de seus alunos, deixando-os motivados com o projeto. Ainda como recursos humanos necessários, há a necessidade de pessoas que cuidem da horta na ausência dos estudantes, de forma deixá-la sempre atrativa para os mesmos.

\subsection{Recursos de Inglês}

O principal recurso da área inglesa do PA é justamente a mentora dele: a professora. Esta participará ativamente das atividades conjuntas com as demais áreas, além de trabalhar no aprendizado dos estudantes da língua inglesa. Podemos ainda contar com o material didático da matéria e as ferramentas tecnológicas previamente citadas para contribuir como recursos desta área.

\section{Análise dos Resultados}

Ao selecionar sementes, calcular a quantidade a ser plantada, adubar o solo, semear e colher, os alunos aprenderam por experimentos. Descobrem e comprovam métodos e técnicas para atingir os objetivos e buscam solução para superar desvios, como, por exemplo a não germinação de algumas sementes ou o declínio dos brotos. É um processo de associações e descobertas. Este nível intenso de interação instiga a pesquisa, motivando o aluno a apropriar-se de uma ciência adaptada a sua real necessidade, através da práxis. Contempla ainda a afetividade como autora motivacional da função cognitiva, retratada nos sentimentos de apreciação dos resultados.

No decurso da produção de objetos de aprendizagem usando o inglês, os conhecimentos prévios permitem aos alunos planejar e antecipar resultados. O empenho perseverante do aprendiz em concretizar um projeto digital o encaminhará ao enfrentamento de desafios antes desconhecidos e imprevisíveis. Estes estímulos não só nortearão a busca do saber para a instrumentalização dos softwares, mas também da língua inglesa, cujo vocabulário e expressões idiomáticas precisam ser adequadas ao contexto sociocultural das situações representadas. A continuidade deste ciclo conduz à reorganização das estruturas cognitivas resultando em aprendizado.

Quanto aos softwares utilizados, percebemos dificuldade na abstração dos conceitos relacionados ao Scratch e ao Freemind, que foram vencidos com o tempo e a exemplificação do uso. A grande contribuição destes e dos demais softwares utilizados foi a possibilidade de os estudantes criarem, de maneira intuitiva, suas próprias produções, tornando-se autores de suas experiências, relatadas por meio da tecnologia. Um exemplo de produção pode ser observada abaixo, assim como o engajamento dos estudantes na produção de animações no Scratch. 

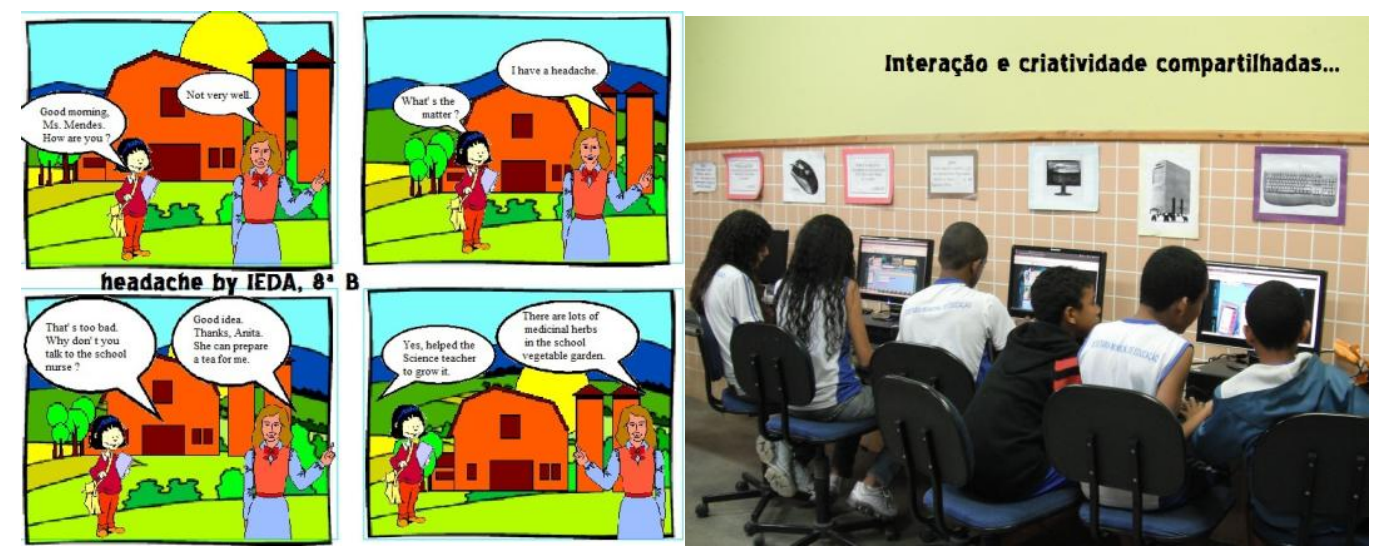

Figura 1: Produções realizadas pelos estudantes.

Sob a perspectiva de ambiente educacional, visualizamos grupos de alunos dialogando sobre as práticas e em permanente sociointeração com seus professores e colegas. O conhecimento é adquirido e organizado internamente, também, no intercâmbio e debate do saber e do fazer. Supõe a integração das sensações, percepções e representações mentais, retratando a mediação operacionalizada em um contexto sociocultural permeado pela palavra. Propicia a transformação mental que conduz à incorporação inconsciente do conhecimento.

No cultivo do solo os alunos podem observar que o desenvolvimento das plantas é ininterrupto e confiável quando recebem o devido cuidado e atenção, quando são respeitadas as etapas de germinação e crescimento até que produzam os frutos esperados. O mesmo princípio pode ser observado na construção do conhecimento. É necessário haver empenho do aluno para aprender; dedicar tempo, esforço e vívido interesse para alcançar suas metas. E assim como as plantas dependem dele para crescer viçosamente, ele também necessita de um professor para mediar seu aprendizado, incentivá-lo e apoiá-lo em suas pesquisas. Assim como interagiu com os colegas na troca de ideias e conclusões, precisa compartilhar seus sucessos para cooperar e, seus fracassos para ser auxiliado.

$\mathrm{Na}$ aprendizagem de uma língua, como na matéria de Inglês, o comportamento cognitivo dos alunos foi constantemente elaborado através de estímulos linguísticos com ênfase nas vivências pessoais. O professor ajudou o aluno a criar modelos explicativos das suas experiências, facilitando a sistematização de observações, o teste de hipóteses e a aplicação de regras numa vasta variedade de circunstâncias. Os mecanismos de pedagogia mediatizada foram especialmente úteis para ajudar os alunos a reorganizar os processos de pensamento e para a restruturação dos processos cognitivos. Os procedimentos mais utilizados pelos professores foram: processos de questionamento; processos de transferência de conhecimentos; provocar ou solicitar justificações; enfatizar a ordem, a predictabilidade, a sistematização e a sequencialização de acções; processos de generalização; e o uso de estratégias cognitivas (processos de atenção, de memória e de problem solving).

Para avaliar o projeto de aprendizagem e consequentemente visarmos o seu aprimoramento, utilizamos o mesmo método utilizado para avaliar os alunos, ou seja, através de suas autoavaliações. Isto porque acreditamos que "o uso das TICs no registro dos PAs é um grande aliado da avaliação. Esse uso permite um registro processual que torna possível uma nova relação com o erro. Afinal todo o processo pode ser 
comparado, revisto, lido pelo próprio sujeito, seus pares e seu educador que o momento é gestado de possibilidades de novas aprendizagens: avaliação dessa forma é ao mesmo tempo resultado e processo, avaliação e autoavaliação e meio de aprendizagem." [Favero, 2012].

\section{Considerações Finais}

Por certo a utilização das TICs pode ajudar consideravelmente na construção do conhecimento de qualquer indivíduo, porém, é importante dominar tais tecnologias para que estas tenham efeito significativo, principalmente, quando tratamos de educação.

Propusemos neste trabalho, visando a aplicação das tecnologias na educação, um Projeto de Aprendizagem visando a inter/transdisciplinaridade das áreas de Inglês, Ciências e Informática. Este projeto encontra-se em desenvolvimento e conta com a colaboração de três professores da rede municipal de ensino de Vitória. Suas atividades foram aqui descritas da maneira que foram sugeridas na escola. Os aplicativos aqui avaliados encontram-se em uso e estão disponíveis livremente na escola e na Internet para os alunos.

Percebemos através desse artigo que o trabalho com projetos de aprendizagem, favorece os professores na coordenação com os trabalhos, aos alunos na troca de experiências e também ao currículo escolar na integração entre conteúdos de diversas disciplinas, atendendo ao que foi proposto durante o trabalho, a interdisciplinaridade, e criando oportunidades para os aprendizes expressarem suas vontades, opiniões, sentimentos, ocasionando a construção da autonomia e autoria para construção do conhecimento, como era o objetivo deste PA.

\section{Referências}

Almeida, M. E. B. (2010) “A Tecnologia precisa estar na Sala de Aula.”, Disponível em: <http://revistaescola.abril.com.br/planejamento-e-avaliacao/avaliacao/entrevistapesquisadora-puc-sp-tecnologia-sala-aula-568012.shtml>. Acesso em 23/05/2012.

Almeida, M. E. B.; Prado, M. E. B. B. (2008) "Desafios e possibilidades da Integração de Tecnologias ao Currículo." Brasília, Ministério da Educação e Secretária de Educação a Distância.

Audino, D. F.; Nascimento, R. S. (2010) "Objetos de Aprendizagem - Diálogos entre Conceitos e uma nova Proposição Aplicada à Educação", Revista Contemporânea de Educação, v.5, n. 10, p.128-148.

Amaral, M. A.; SÁ, H. S.; VASCO, A. M.; BARTHOLO, V. F. (2009) “Trabalho com Alunos Multiplicadores para Aplicação de Objetos de Aprendizagem no Ensino Curricular", Anais do XX SBIE - UFSC e UNIVALI.

Bernadi, M.; Behar, P. A. (2004) , “A Introdução das TIC na Formação de Professores: Um Estudo no Curso de Pedagogia”, Anais do XV SBIE - UFAM.

FÁVERO, R. P. (2012) "Projetos de Aprendizagem e as Tecnologias da Informação e da Comunicação". Instituto Federal do Espírito Santo - IFES. 
Fialho, N. N.; Matos, E. L. M. (2010), “A Arte de Envolver o Aluno na Aprendizagem de Ciências utilizando Softwares Educacionais”. Revista Educar, Curitiba.

Fagundes, L. Sato, L. S.; Maçada, D. L. (1999) "Aprendizes do Futuro: as Inovações Começaram", Revista Coleção Informática para a Mudança na Educação. Brasília: MEC/SEED/PROINFO.

Prado, M. E. B. B. (2003) , "Pedagogias de Projeto: Fundamentos e Implicações" , Boletim do Salto para o Futuro. Brasília: TV-ESCOLA-SEED-MEC.

Silva, C. R. O. (1998), "Bases pedagógicas e Ergonômicas para a Concepção e Avaliação de Produtos Educacionais Informatizados” . PPGEP/UFSC. 